\title{
Avaliação institucional e trabalho docente: repercussões, desafios e perspectivas ${ }^{1}$
}

\author{
Institutional assessment and teatching work: repercussions, challenges and \\ perspectives \\ Evaluación institucional y trabajo docente: repercusiones, desafíos y \\ perspectivas
}

\section{LÚCIA MARIA DE ASSIS}

Resumo: Este artigo apresenta os resultados de uma pesquisa bibliográfica, em estudos publicados entre 1996-2013, que buscou apreender como as políticas de avaliação institucional repercutem no trabalho dos professores da Educação Superior. A metodologia foi traçada a partir de uma busca em periódicos educacionais, comunicações da Anped, bem como em Teses e Dissertações. Fundamenta-se em Dias Sobrinho (2002, 2003), Sguissardi \& Silva Jr. (2009), Sguissardi 2014), Freitas (2012) e Afonso (2012). Conclui-se que a avaliação institucional, pautada nos resultados do Enade, tem priorizado os aspectos formais em detrimento dos aspectos formativos e, por isso, tende a esgotar seu potencial de estimular a melhoria acadêmica nas IES. Tem aumentado, também, a tensão junto aos docentes por melhores resultados no ranking, e definido os currículos dos cursos de modo a adequá-los à prova do Enade.

Palavras-chave: Política educacional; educação superior; avaliação institucional; trabalho docente.

\begin{abstract}
This article presents the results of a bibliographical research that sought to understand how institutional evaluation policies influence on the work of higher education teachers in studies published during 1996-2013. The methodology was drawn from a research in educational journals, communications from Anped, theses and dissertations. This paper is based on Dias Sobrinho (2002, 2003), Sguissardi (2009, 2014), Freitas (2012) and Afonso (2012). It is concluded that the institutional assessment guided on Enade results has given priority to formal aspects to the detriment of the educational aspects. That way, it tends to exhaust its potential to stimulate academic improvement in IES. It has also increased the tension with the teachers for better results on the ranking, and set the curricula of the courses in order to adapt them to the test of Enade.
\end{abstract}

Keywords: Educational policy; higher education; institutional assessment; teaching work.

11 Este artigo apresenta uma síntese dos estudos realizados em estágio pós-doutoral intitulado "O trabalho docente face às políticas de avaliação institucional da educação superior no Brasil no período de 19962013", e é parte do Projeto integrado Expansão da Educação Superior e produção do conhecimento: financiamento, gestão e avaliação financiado pela CAPES, "Casadinho" USP-UFG. 
Resumen: Este artículo presenta los resultados de una investigación bibliográfica, en estudios publicados entre 1996-2013, que busca aprehender cómo las políticas de evaluación institucional tienen repercusiones en el trabajo de los profesores la educación superior. La metodología se elaboró a partir de una búsqueda en periódicos educacionales, comunicaciones de ANPED, así como en tesis y disertaciones. Se basa en Dias Sobrinho (2002, 2003), Sguissardi \& Silva Jr. (2009), Sguissardi (2014), Freitas (2012) y Afonso (2012). Se concluye que la evaluación institucional, basada en los resultados de ENADE, ha dado prioridad a los aspectos formales, en detrimento de los aspectos de formación y, por lo tanto, tiende a agotar su potencial para estimular la mejora académica en las IES. También se ha ampliado la tensión junto a los docentes para obtener mejores resultados en el ranking, y definido los currículos de los cursos con el fin de adaptarlos a la prueba de ENADE.

Palabras clave: Política educativa; educación superior; evaluación institucional; trabajo docente.

\section{INTRODUÇÃO}

Campo de estudos amplamente aberto e difundido na área educacional nas últimas décadas, a avaliação vem ganhando centralidade nos debates contemporâneos, tanto para a definição de políticas públicas para a área educacional quanto para a orientação das práticas educativas dos professores dentro das salas de aula (DIAS SOBRINHO, 2002). Além disso, também tem tido enorme repercussão midiática através da divulgação de rankings elaborados para todos os níveis educacionais a partir dos resultados de exames de larga escala, provocando polêmicas, mobilizando famílias e modificando as relações estabelecidas no interior das instituições escolares e universitárias (ASSIS; AMARAL, 2013).

Quanto à educação superior no Brasil, desde 1996 realiza-se a avaliação das Instituições de Educação Superior (IES) públicas e privadas por meio da aplicação de um exame nacional, quando foi criado o Exame Nacional de Curso (ENC-Provão) $^{2}$. Em 2003, após a eleição do presidente Luis Inácio Lula da Silva, instituiu-se a Comissão Especial de Avaliação (CEA), composta por um grupo de pesquisadores e representantes do MEC, para propor uma nova forma de

2 O Exame Nacional de Cursos (ENC-Provão) foi um exame aplicado aos formandos, no período de 1996 a 2003, com o objetivo de avaliar os cursos de graduação da Educação Superior, no que tange aos resultados do processo de ensino-aprendizagem. Disponível em: http://portal.inep.gov.br/enade/enc-provao. Consulta em: 07 jun. 2016. 
proceder à avaliação das IES, tendo em vista as inúmeras críticas ao modelo vigente ${ }^{3}$.

Em 2004, o ENC foi substituído pelo Sistema Nacional de Avaliação da Educação Superior (Sinaes), criado pela Lei n 10.861, de 14 de abril de 2004, e, diferentemente do modelo anterior, passou a combinar componentes relativos ao ensino, à pesquisa, à extensão, à responsabilidade social, ao desempenho dos alunos, à gestão da instituição, ao corpo docente, às instalações, dentre outros aspectos ${ }^{4}$. Trata-se, portanto, de um modelo mais abrangente e complexo.

Observa-se que a avaliação das IES passa a cumprir um importante papel como instrumento de monitoramento da qualidade educacional, na medida em que combina os resultados de desempenho dos estudantes com a autoavaliação institucional e a avaliação externa realizada por especialistas, conforme prevê as orientações do Sinaes. Entretanto, outras finalidades também passaram a ser atribuídas às avaliações das IES, como por exemplo, a responsabilização os gestores e docentes pelos resultados obtidos pelos estudantes no Exame Nacional de Desempenho dos Estudantes, o Enade, e, consequentemente, nos conceitos gerais obtidos pelos cursos e pelas IES.

Esta responsabilização tem desencadeado algumas consequências para as IES, em especial para as instituições privadas, que podem ser observadas, sobretudo, na necessidade de adequação dos seus projetos institucionais, da sua infraestrutura quanto à rede física, instalações, acessibilidade, atualização de acervo bibliográfico e espaços de laboratórios e do seu corpo docente, quanto à titulação e dedicação parcial e/ou integral à IES. Se, por um lado, a melhoria das condições de funcionamento das IES podem ser consideradas um avanço do ponto da qualidade, por outro, o efeito na organização curricular poderá induzir a uma padronização que atenda às características dos exames em larga escala, promovendo um perigoso reducionismo na formação dos estudantes. Segundo Freitas (2012) este cenário tende a fortalecer as empresas privadas que elaboram, vendem e divulgam o ensino apostilado e ainda promove a responsabilização dos professores pelos resultados dos exames. O resultado disso quase sempre

\footnotetext{
3 Dentre as críticas se destaca a centralidade do exame nacional e padronizado coordenado pelo Inep, obrigatório para todos os formandos em cursos de graduação, cujo resultado, divulgado amplamente sob a forma de ranking, poderia implicar em consequências para as IES que não atingissem o conceito mínimo por duas avaliações consecutivas. Tais consequências variavam desde a suspensão de novas vagas até o descredenciamento do curso que não cumprisse os termos de ajustamento propostos pelas Comissões Avaliadoras.

4 "O Sinaes possui uma série de instrumentos complementares: autoavaliação, avaliação externa, Enade, avaliação dos cursos de graduação e instrumentos de informação (censo e cadastro). Os resultados das avaliações possibilitam traçar um panorama da qualidade dos cursos e das instituições de Educação Superior no País. Os processos avaliativos são coordenados e supervisionados pela Comissão Nacional de Avaliação da Educação Superior (Conaes). A operacionalização é de responsabilidade do Inep”. Disponível em: http:// portal.inep.gov.br/superior-sinaes. Consulta em: 07 jun. 2016.
} 
é a consolidação de mecanismos de regulação e de intensificação do trabalho docente.

Considerando a importância dos processos de avaliação das IES, bem como as suas inúmeras tensões e contradições, buscamos identificar e analisar o que os estudos e pesquisas em educação vêm concluindo sobre as possíveis repercussões dessas políticas no trabalho dos professores. Para isso realizou-se um estudo bibliográfico para saber como e em que medida, as políticas de avaliação institucional, implementadas por meio do Exame Nacional de Cursos (ENC), que vigorou de 1995 a 2003, e do Sistema Nacional de Avaliação das Instituições de Ensino Superior (Sinaes), iniciado em 2004 e ainda em vigor, estão influenciando o trabalho dos professores dentro das instituições de Educação Superior (IES).

É preciso destacar que o Sinaes, implantado em 2004, vem passando por inúmeras modificações, sendo a mais significativa o excesso de protagonismo dado ao Exame Nacional de Desempenho dos Estudantes, o Enade, em detrimento dos outros dois componentes que formam o tripé da avaliação institucional a autoavaliação e a avaliação externa. A centralidade do exame foi coroada em 2008 com a criação do Conceito Preliminar de Cursos (CPC) e do Índice Geral de Cursos (IGC) ${ }^{5}$ que resumem todo o processo avaliativo em números, rapidamente transformados em rankings para deleite e espetacularização dos meios de comunicação e das IES privadas, que usam esses dados para divulgarem peças publicitárias que atestem sua "qualidade comprovada pelo MEC" (SOUSA, 2009).

Neste estudo, o trabalho docente é caracterizado por todas as atividades desenvolvidas pelos professores relacionadas ao ensino, pesquisa, extensão e gestão institucional no âmbito das relações estabelecidas com a instituição de ensino, considerando-se seus fins e objetivos, visando a abranger os aspectos do processo de ensino, de produção e socialização do conhecimento (MAUÉS, 2011).

O percurso metodológico deste estudo foi traçado a partir de uma pesquisa bibliográfica acerca do período 1997-2013, em 12 periódicos da área educacional, disponíveis no sítio Scielo, comunicações orais apresentadas nos Grupos de Trabalhos 8 (Formação de Professores), 9 (Educação e Trabalho) e 11 (Política da Educação Superior) da Anped e Teses e Dissertações consultadas nos

5 Sobre o CPC e o IGC ver <http://portal.inep.gov.br/educacao-superior/indicadores > (acesso em 01/09/2015). 
arquivos da Biblioteca Digital de Dissertações e Tese (BDDT-IBICT) e, por fim, o sítio da Capes, relativas aos anos 2011 e $2012^{6}$.

A pesquisa foi realizada utilizando-se as palavras e expressões-chaves que remetem à questão central desta investigação: trabalho docente, avaliação institucional, educação superior, "ensino superior, Sinaes. Foram identificados 110 estudos, sendo 40 artigos e 70 teses e dissertações. Destes, foram selecionados 23 estudos, nove artigos e 14 teses e dissertações.

Os 23 estudos foram selecionados por apresentarem, de modo geral, alguma repercussão da avaliação nas IES; entretanto, o desafio deste estudo foi o de apreender as repercussões no trabalho dos professores. Observou-se que as repercussões da avaliação institucional nas IES ocorrem de forma emblemática, pois, ao mesmo tempo em que podem introduzir novos paradigmas de gestão acadêmica de um curso, por exemplo, estimulando o diálogo e as trocas de experiências entre os docentes e uma maior participação de todos nas decisões sobre o projeto de um curso, também acarreta aumento de trabalho para os professores, que precisam dedicar mais tempo à participação em reuniões, encontros, jornadas, seminários, dentre outros, sem os quais não é possível uma construção coletiva do projeto pedagógico dos cursos.

Dos trabalhos previamente selecionados nos periódicos e anais dos três GTs da Anped, nove artigos foram considerados para efeito deste estudo, por abordarem as relações entre avaliação institucional e trabalho dos professores, seja tratando das macropolíticas educacionais, incluindo o Sinaes, seja focando o estudo somente em um dos aspectos do Sinaes, como a autoavaliação institucional. As análises que apresentamos referem-se aos resultados dos artigos de Avila (2011), Ribeiro (2012), Martins (2000), Maués (2008), Niches (2011), Silva (2011), Sousa (2011), Souza \& Real (2009) e Tiradentes (2010).

Dos bancos de dissertações e teses foram selecionados 14 estudos para análise utilizando-se os mesmos critérios empregados para os artigos. As conclusões desse grupo apresentam duas tendências: os que constataram não ter a avaliação institucional influência sobre o trabalho docente, em geral em pesquisas desenvolvidas em instituições específicas, do tipo estudos de casos; e aqueles que constataram ter ela que influência significativa, tanto contribuindo para a melhoria dos trabalhos dos professores, quanto induzindo o currículo às

\footnotetext{
6 Em 2014, a página da CAPES informou que devido a atualizações em seu sistema de armazenamento de arquivos, os dados dos anos anteriores não estariam disponíveis e que, após a conclusão do processo de transição, os demais arquivos voltariam a ser disponibilizados. Entretanto, o prazo deste estudo não permitiu a espera e, por isso,

fizeram-se constar nele apenas os anos 2011 e 2012. Grande parte do acervo da CAPES também esta disponível na BDDT-IBICT, o que contribuiu para não comprometer os objetivos deste estudo.
} 
características dos exames do Enade, entre outros casos. Há, ainda, aqueles que apresentam as duas tendências no mesmo estudo. As pesquisas analisadas foram Andriola (2011), Assis (2008), Bertelli (2004), Conceição (2011), Correia (2012), Costa (2007), Fonseca (2006), Marins (2012), Mota Junior, (2011), Oliveira (2011), Silva (2008), Sanches (2010), Sousa (2012) e Wordell (2012).

Para uma melhor apreensão dos resultados, inicialmente serão apresentados os estudos realizados na vigência do ENC e, em seguida, os na vigência do Sinaes, tendo em vista as diferenças dos contextos sociais, econômicos e políticos que marcam o período de vigência dos dois modelos, bem como suas características quanto aos princípios e concepções, metodologia, instrumentos e usos dos seus resultados.

\section{O QUE DIZEM AS PUBLICAÇÕES SOBRE AVALIAÇÃO E TRABALHO DOCENTE NA VIGÊNCIA DO ENC}

Iniciando pelos estudos relativos ao período de vigência do $\mathrm{ENC}^{7}$, Souza e Real (2009) se baseiam em análises de relatórios das comissões de especialistas em visitas in loco durante 1995 a 2002.

As autoras constataram que, ao mesmo tempo em que as universidades privadas foram pressionadas para atender aos indicadores estabelecidos a partir do ideal de qualidade das universidades públicas, estas foram vivenciando um processo inverso, que, por meio da escassez de recursos, implicou a não atualização das instalações físicas e condições para o trabalho acadêmico, agravada pela aposentadoria precoce de professores, o que se traduziu na contratação de professores temporários, muitas vezes menos qualificados, conforme registros em relatórios elaborados por comissões de especialistas.

O estudo revela que as evidências coletadas indicam que as modificações ocorridas não se fizeram de modo igual nas instituições públicas e privadas e que o "poder indutor da avaliação usualmente leva a uma qualidade formal em detrimento de uma qualidade real e que a sistemática de avaliação, tal como delineada, tende a esgotar seu potencial de estimular alterações nas instituições" (SOUZA; REAL, 2009, p. 483).

Dessa forma, os efeitos das políticas que promoveram a flexibilização, a expansão e a privatização da educação superior nos anos 1990, marcadas por baixo investimento nas instituições federais de educação superior (IFES), levaram

7 O Exame Nacional de Cursos (ENC-Provão) foi um exame aplicado aos formandos, no período de 1996 a 2003, com o objetivo de avaliar os cursos de graduação da Educação Superior, no que tange aos resultados do processo de ensino-aprendizagem. Disponível em: http://portal.inep.gov.br/enade/enc-provao. Consulta em: 07 jun. 2016. 
à não realização de concursos públicos para a reposição do quadro de professores aposentados. Em consequência, grande parte das vagas foi preenchida por professores em contratos temporários de trabalho. O estudo capta esse movimento expansionista, revelando a avidez das IES privadas em adequar seus quadros de professores às novas exigências do MEC no que se refere à titulação e dedicação integral, enquanto as IFES perdem os seus professores mais experientes, que são substituídos por docentes temporários, e, portanto, não possuem vínculo com as instituições (SGUISSARDI; SILVA JR , 2009).

O estudo revela, ainda, que o ENC operou mudanças nas IES, mas não ensejou melhorias significativas dos cursos, na medida em que não conseguiu promover uma qualidade efetiva ou "real", conforme constataram Souza e Real (2009).

$\mathrm{Na}$ mesma direção, Martins (2000) investigou as repercussões do ENC na PUC Minas quando foi divulgado o primeiro resultado do Exame e o curso de Odontologia em análise obteve conceito C. A autora relata que "o anúncio do resultado em 1997 (C em todos os quesitos) trouxe constrangimento e revolta na comunidade acadêmica, até então considerado como modelo inovador e desbravador de ensino e da prática odontológica” (p. 11). As consequências imediatas incidiram no quadro docente, com a demissão de $41 \%$ dos professores. Embora a demissão tenha possibilitado um rearranjo numérico na qualificação docente e no tempo de dedicação dos professores que permaneceram, permitindo contabilizar 2 quesitos com conceito B, a migração de conceito no resultado do ENC teve que aguardar 2 anos. (Idem).

O resultado desse estudo de caso mostra uma tendência das IES privadas no sentido de se ajustarem aos padrões de "qualidade" do ENC e de se "adequarem a estes parâmetros que atingiram em cheio o projeto original do curso e a sua "vocação extensionista" (Idem, p. 14). Nesse contexto

Muitos professores foram demitidos; a carga horária prática foi reduzida; clínicas extramuros que atendiam a população carente foram fechadas; o currículo foi adaptado ao ENC; professores doutores desvinculados completamente do histórico e da trajetória inovadora do Curso foram contratados. Todos esses fatores contribuíram para a descaracterização completa da vocação social e do projeto original do referido Curso (Idem, p. 19).

Esta constatação vai ao encontro das conclusões de Souza e Real, (2009) quanto ao fato de o ENC promover uma qualidade formal dos cursos, que nem sempre significa uma melhoria da qualidade real.

Nessa mesma linha de análise, os estudos de Avila (2011) investigaram como os trabalhos aprovados na Anped entre 1996-2009 mostram e analisam o trabalho docente na educação superior no contexto de reformas de cunho 
privatista e regulatório implantadas nos anos 1990. A autora concluiu que a avaliação tornou-se importante ferramenta para promover: 1) a precarização do trabalho docente, vinculada principalmente à baixa remuneração, à fragmentação, à desqualificação e à perda do status social; 2) a descentralização gerencial, que traz uma visão ilusória de colaboração no processo, mas que, na verdade, esconde a ausência de autonomia com relação ao trabalho; 3) a submissão aos sistemas avaliativos, tanto dos docentes quanto das instituições, que tem por finalidade a eficiência e a produtividade do professor, 4) a flexibilização do trabalho, tanto no que diz respeito aos contratos de trabalho precários quanto no que se relaciona ao crescente número de tarefas, quando o professor deixa de ser responsável apenas pelo ensino e pela pesquisa, passando a ser um gestor de trabalhos burocráticos como relatórios, formulários, pareceres e até captação de recursos e, por último, o que talvez englobe todos os itens anteriores, 5) a intensificação e extensão do tempo de trabalho docente (AVILA, 2011).

\section{O QUE DIZEM AS PUBLICAÇÕES SOBRE AVALIAÇÃO E TRABALHO DOCENTE NA VIGÊNCIA DO SINAES}

Os trabalhos publicados na vigência do Sinaes apresentam enfoques diversificados, podendo abordar um ou mais componentes do sistema. Para conhecer as repercussões da autoavaliação institucional no trabalho docente numa IES pública e numa privada, o estudo de Ribeiro (2012) mostrou que os resultados dessa avaliação são divulgados sob a forma de relatórios consolidados pela Comissão Própria de Avaliação (CPA) e que cada IES organiza e conduz esses trabalhos de maneira bem específica de acordo com a sua tradição em avaliar o trabalho docente. De acordo com as orientações do Sinaes, cada curso tem sua autoavaliação conduzida e sistematizada pelos Núcleos Docentes Estruturantes (NDE) e enviados às Comissões Próprias de Avaliação (CPA), que realizam o consolidado institucional.

Trata-se, portanto, de uma etapa da Avaliação potencialmente propositiva, cujos resultados poderão estimular análises e reflexões entre os docentes. Para Ribeiro (2012), “alguns aspectos relacionados à docência estão sendo alterados, com maiores mudanças nos aspectos relativos ao relacionamento professor-aluno nas IES privadas e na condução das aulas nas IES públicas” (p. 311). Segundo a autora, "O resultado produzido [...] permite-nos afirmar que os docentes, ao vivenciarem um processo de avaliação significativo para seu crescimento, refletirão na descoberta de uma melhor maneira de ensinar" (Ibidem).

No caso da IES privada, um elemento relacionado à melhoria da qualidade do desempenho do docente é a aceitação do trabalho por ele desempenhado 
conforme o que determinam os padrões da instituição; já na instituição pública, esse elemento é irrelevante, considerando-se a autonomia acadêmica de que gozam os docentes dessas IES. Ainda para a autora,

\begin{abstract}
Em um processo de avaliação docente, quanto mais os professores observam que o processo irá produzir satisfação, sugestões para melhoria das atividades desenvolvidas, alguma forma de incentivo à capacitação, eles tendem a se envolverem e aceitarem a proposta de avaliação e a utilizarem os resultados para refletir e agir sobre o seu trabalho (Idem, p. 313).
\end{abstract}

Entretanto, a autora alerta também que, embora a perspectiva trazida pelo Sinaes de se estabelecer e se desenvolver de forma efetiva como sistema de avaliação para a educação superior, orientado pelos princípios articulados de formação e regulação, este teve sua finalidade descaracterizada, no início de 2008, ao promover o deslocamento da avaliação institucional do centro do processo regulatório das IES para a utilização dos resultados dos dois índices criados - Conceito Preliminar de Curso (CPC) e Índice Geral de Cursos (IGC) "em atitude arbitrária do governo" (ibidem, ). Mesmo assim ficou evidente que a autoavaliação institucional, na dimensão da avaliação docente, "tem se firmado pela repercussão de que os resultados têm produzido ressignificações na gestão administrativa e acadêmica nas/das IES e nos/para os atores institucionais" (Idem, p. 316). Conclui-se, portanto, que a avaliação institucional está incorporada aos processos acadêmicos das IES, com viável possibilidade de já se poder falar em uma cultura avaliativa.

Diferentemente de Ribeiro (2012) que focou sua análise na repercussão da autoavaliação institucional no trabalho docente, ou seja, um recorte que considera somente um dos indicadores que compõem o Sinaes, Olgaíses e Maués (2008) apresentam o resultado de um estudo bibliográfico e documental, que buscou identificar as relações existentes entre a reforma do Estado, as tendências da educação traduzidas pelas políticas educacionais e o estabelecimento de novas regulações no tocante à formação e ao trabalho docente. As autoras destacam que a "regulação pós-burocrática (Estado-avaliador e quase mercado) formula os objetivos a serem atingidos e definem os diferentes tipos de avaliação externa que vão verificar os resultados obtidos por esses profissionais" (p. 9). No caso dos docentes da educação superior, esta relação é reforçada pela Avaliação de Cursos promovida pelo Sinaes, por meio da qual

O Estado Avaliador estipula as metas a serem atingidas e os mecanismos de verificação dos resultados. O docente precisa atingir tais metas sob pena de [que] a instituição ao qual está vinculado deixe de receber recursos, como uma forma de penalização (Ibidem). 
Esta conclusão conduz ao que Tardif denominou "lógica baseada nos critérios de eficácia e de sucesso, ou seja, nos parâmetros do mercado" (Tardif, apud MAUÉS, 2008, p. 10). Nesse caso, a obrigação de resultados em educação nada mais é do que um esforço para fazer com que as instituições escolares entrem na lógica da ação instrumental própria da modernidade, tese reforçada por Sguissardi e Silva Jr (2009).

Já o estudo de Sousa (2011) focou as repercussões do Exame Nacional de Desempenho dos Estudantes (Enade) no interior de uma IES e teve como objetivo observar como os coordenadores de cursos de uma universidade pública (UnB) utilizam esse resultado no desempenho das suas funções na coordenação. Os resultados mostram que "em sua maioria, as coordenações dos cursos pesquisadas não transformaram os resultados do Enade 2008 em estratégias para o desenvolvimento do trabalho acadêmico dos seus respectivos cursos" e as razões mais identificadas são: (1) não valorização do Enade como política avaliativa; (2) desconhecimento dos aspectos conceituais e metodológicos desse exame; (3) descontinuidade nos cargos de coordenação de curso no período de 2008 a 2010. Na prática, em sua maioria, os cursos não introduziram mudanças significativas em sua organização pedagógica e, "no caso daqueles que sinalizaram mudanças, estas não se relacionam, necessariamente, com os conceitos obtidos no exame”. (SOUSA, 2011, pp. 13-14).

Esse estudo mostra que a avaliação institucional tem poucas repercussões nas IES públicas, cujos docentes possuem autonomia acadêmica historicamente assegurada. Ao contrário do que ocorre nas IES privadas, a autonomia docente é subordinada aos interesses mais imediatos definidos pelo mantenedor, sobretudo no que diz respeito aos efeitos da divulgação de resultados negativos na grande mídia e como esses resultados poderão impactar a demanda de alunos nos anos seguintes (ASSIS, 2008). Soma-se a isso o fato de uma boa avaliação do Enade ser condição para que as IES privadas possam ser parceiras do governo federal na concessão de Bolsas de Estudos pelo Prouni, programa voltado para a compra de vagas nas IES privadas, pelo governo federal, destinadas a estudantes que não podem arcar com os custos de mensalidade.

Explorando outra dimensão do Sinaes, Silva (2011) analisou relatórios das Comissões Próprias de Avaliação (CPA), tendo como referência as alterações que se processam na política de avaliação da educação superior com a introdução do CPC e do IGC. O estudo permitiu observar algumas repercussões do Sinaes em duas IFES e conhecer o papel que a avaliação institucional vem cumprindo, bem como identificar suas possibilidades como mecanismo para formulação de políticas institucionais. 
Por meio de dados coletados junto às CPAs da Universidade Federal de Pernambuco e na Universidade Federal do Rio Grande do Norte, o autor constatou várias dificuldades enfrentadas pelos membros dessas CPAs. O trabalho enumerou nove problemas que têm dificultado os trabalhos dessa comissão: (1) dificuldade quanto ao diálogo das CPAs com as estruturas centrais do Sinaes, materializado na Comissão Nacional de Avaliação Educacional (Conae) e no INEP, no que se refere à obtenção de informações, divulgação e interpretação dos resultados; (2) dificuldade para acompanhar as "novidades" do Sinaes, pois as mudanças não são socializadas pelas IFES por meio de canais adequados e sistemáticos; (3) problemas no trabalho da comissão com os dados levantados por meio dos indicadores relativos à capacidade de tempo, recursos humanos, infraestrutura e material, em etapas diversas do processo, mas, sobretudo, na etapa de análise dos dados, dentro dos prazos estabelecidos; (4) dúvidas sobre o papel efetivo da CPA - falta de formação e informação; (5) fragilidade muito acentuada no processo de mobilização, pela CPA, da comunidade acadêmica dos diversos centros acadêmicos, departamentos e cursos, na articulação da participação e envolvimento dos professores, estudantes e funcionários; (6) dificuldade de se apropriar da totalidade da documentação exigida pelo Sinaes; (7) limitações por parte dos membros da CPA para realizar a análise dos dados levantados durante o processo de avaliação; (9) dificuldades referentes ao espaço físico, estrutura e material de expediente, bem como melhores condições para o trabalho das comissões, já que era comum a queixa relativa ao excesso de atividades por parte de seus membros.

Destacam-se as dificuldades para a mobilização e o envolvimento dos professores nos debates acerca da avaliação e as condições de trabalho dos membros da Comissão, que, em geral, acumulam funções, acarretando o sobretrabalho ou a intensificação da jornada dos professores envolvidos. Esses elementos se referem aos aspectos denominados por Dias Sobrinho (2000) 'aspectos sociais' e de 'funcionamento' da avaliação institucional. É importante ressaltar que o conceito de avaliação institucional se refere, no contexto do Sinaes, à articulação da avaliação interna, externa e da reavaliação, sendo a primeira a base geradora do Sistema de avaliação, amparada na avaliação de Cursos e do desempenho estudantil. (SILVA, 2011, p. 11).

Outro ponto que esse estudo apresenta refere-se às mudanças dos rumos, dos sentidos e dos objetivos da avaliação institucional após a criação dos índices que transformam o sentido da avaliação formativa, processual e multirreferencial, enfatizando os resultados e os produtos em detrimento dos processos. Essa lógica contribuiu para esvaziar de sentido a autoavaliação, dado que converge com as 
análises apresentadas por Ribeiro (2012), em que a avaliação tende a assumir um viés classificatório e ranqueador das instituições e cursos.

Segundo Dias Sobrinho (2010), essa prática avaliativa “é característica do paradigma objetivista e inviabiliza o processo de sensibilização defendido por uma avaliação baseada no paradigma democrático" (p.12), uma vez que o debate em torno da qualidade ofertada nas IFES possivelmente tenderá a ser verticalizado, desvinculando-se do âmbito da comunidade acadêmica para os quadros burocráticos do governo.

$\mathrm{Na}$ mesma linha de investigação, Assis (2008) analisou as repercussões do Sinaes em três IES, sendo duas privadas e uma pública federal. O estudo revelou que a avaliação institucional não causou grandes impactos na docência da universidade pública, mas trouxe mudanças na prática pedagógica das instituições privadas, sobretudo no que se refere às necessárias adequações de seus planos de cursos aos exames do Enade. Observou também que as IES promoveram amplas mudanças na organização e na gestão do trabalho dos professores por meio de ajustes que visavam a adequar o perfil de formação e dedicação dos docentes aos critérios de avaliação dos cursos e das IES. Para alcançar os percentuais de titulados (mestres e doutores), as IES privadas reduziram o número de professores, concentrando maior carga horária em sala de aula. Nos dois casos de IES privadas analisados, $75 \%$ dos professores, em média, tinham contrato de trabalho como aulistas, sem carga horária remunerada para as atividades extraclasse.

O estudo revelou, ainda, que no período de 1996-2006, a avaliação das instituições foi fortemente influenciada pelos princípios neoliberais, no bojo de acelerado processo de expansão, privatização e diferenciação das IES brasileiras e que esse contexto vinha influenciado a docência, destacando-se aspectos da formação, profissionalização e condições efetivas de trabalho. Outra importante constatação desse estudo é uma ascendente intensificação do trabalho docente, acompanhada de pressões institucionais por maior produtividade acadêmica e um alinhamento das concepções de formação às orientações mercadológicas, com forte apelo para o atendimento às demandas do setor produtivo e do mercado de trabalho, sobretudo nas IES privadas analisadas. Segundo os coordenadores de curso ouvidos, a avaliação institucional tem afetado a vida dos professores, tendo em vista que os resultados dos exames passaram a justificar a reestruturação dos quadros docentes, a reorganização curricular e a flexibilização dos contratos de trabalho.

Em estudo que focou uma IES pública, Sanches (2010) estudou os resultados da avaliação institucional na Universidade Estadual de Goiás (UEG) e constatou que, devido ao fato de a avaliação ter sido coordenada e organizada por uma equipe externa à unidade de ensino pesquisada, "não houve sensibilização 
adequada da comunidade acadêmica para que todos se envolvessem no processo". Segundo ela, o processo avaliativo resumiu-se "na coleta de dados quantitativos com uma divulgação tímida, não servindo aos interesses da comunidade acadêmica, nem para implementar melhorias na gestão e nas práticas pedagógicas docentes". Assim, a avaliação não conseguiu mobilizar e envolver a comunidade acadêmica, tampouco promover mudanças significativas, cumprindo tão somente uma função burocrática.

A avaliação institucional nesses moldes contraria as orientações do Sinaes, que, a despeito da grande diversidade institucional brasileira, salienta que "cada instituição tem a sua história e constrói concretamente suas formas e conteúdos próprios que devem ser respeitados. [...] a avaliação deve servir de instrumento para aumentar a consciência sobre a identidade e, portanto, as prioridades e potencialidades de cada instituição em particular" (SINAES, 2007, p. 94). O mesmo documento também assinala que a identidade institucional é "uma construção que tem a ver com a história, as condições de produção, os valores e objetivos da comunidade, as demandas concretas, as relações interpessoais" (idem, p. 95). Dessa forma, um processo avaliativo só conseguirá lograr êxito se for capaz de satisfazer esses princípios, o que dificilmente será possível em um movimento de fora para dentro.

Já Andriola (2011) partiu do princípio de que, como o docente ocupa seu tempo predominantemente com atividades de ensino, seria necessário pesquisar e documentar as atividades dos professores nessa área, tanto na graduação como na pós-graduação. Pautando-se pelas dimensões propostas pelo Sinaes, o autor fez uma avaliação diagnóstica do docente nas dimensões relativas às atividades da sala de aula. O estudo detectou que, na visão dos participantes da pesquisa, o trabalho dos professores daquela instituição foi muito bem avaliado nas dimensões analisadas (planejamento e gestão das atividades de ensino; didática empregada; usos dos resultados das avaliações; comunicação e interação com os estudantes). O autor fez sua pesquisa logo após o encerramento do primeiro ciclo do Sinaes, o que pressupõe que a instituição tenha informado aos professores sob quais indicadores seu trabalho seria avaliado e que os docentes tenham-se organizado em torno dessa demanda. Nesse sentido, é possível inferir que a avaliação institucional repercutiu no trabalho docente de maneira propositiva.

É interessante ressaltar que esse trabalho se destaca por acentuar aspectos favoráveis da avaliação institucional em IES privadas. Mas, também é bom ressaltar que o recorte do autor ficou circunscrito aos aspectos pedagógicos e didáticos do trabalho docente, não imergindo nas esferas de gestão e adequação institucional aos parâmetros postos pela avaliação das condições de oferta (ACO) e aos resultados do desempenho dos estudantes (Enade). Desse modo, pode-se 
dizer que, do ponto de vista do trabalho em sala de aula, o Sinaes se mostrou favorável a um melhor desempenho dos docentes, sob o olhar deles próprios e dos estudantes.

Wordell (2012) investigou as percepções dos gestores, professores e alunos em cursos de Pedagogia e as razões por eles atribuídas ao conceito 5 no Enade de 2008. O foco do estudo foi compreender como as políticas públicas de avaliação das instituições se materializam nas IES privadas e que sentido elas tem para os sujeitos da pesquisa. Os resultados revelaram que todos os entrevistados perceberam o Enade em um contexto de avaliação formativa e como instrumento para "medir a qualidade dos cursos superiores e uma forma de alcançá-la" (WORDELL, 2012, p. 112).

Para os sujeitos da pesquisa, um curso tem qualidade quando prepara os alunos para o mercado de trabalho, quando está relacionado à formação humana do sujeito e ao preparo para o exercício da cidadania. Todavia, para a maioria dos alunos, o sentido da qualidade foi associado à obtenção de bons resultados no Enade. Em razão da centralidade adquirida por esse exame no contexto da avaliação da Educação Superior, as críticas a ele referentes foram poucas e superficiais por parte dos sujeitos participantes da investigação.

$\mathrm{O}$ autor constatou algumas diferenças entre as percepções dos sujeitos pesquisados nas duas instituições investigadas quanto ao alto desempenho dos alunos: os sujeitos da IES do Maranhão atribuíram os bons resultados obtidos pelos alunos "à coesão e união do grupo de professores e à forma como relacionavam a teoria com a prática" (p. 115). Nas falas desses entrevistados transpareceu a ideia de que a instituição se preocupava com a aprendizagem dos alunos e "todos os sujeitos assumiram a posição de prepará-los para o Enade por meio da adequação do trabalho docente à prova do Enade, aulas preparatórias, simulados e atividades de motivação e esclarecimentos sobre o exame" (ibidem).

Em relação à outra instituição, situada no estado da Bahia, a percepção dos sujeitos entrevistados foi de que "os bons resultados foram alcançados devido à gestão participativa, à metodologia de ensino adotada, à avaliação formativa e à política de formação continuada dos professores" (ibidem). O discurso assumido pela maioria dos sujeitos entrevistados nesta segunda instituição foi orientado para "a ideia de que a gestão curricular do curso não tomava decisões em função do Enade, perspectiva que se tornou incoerente com a prática por algumas ações documentadas e por alguns outros depoimentos coletados" (WORDELL, 2012, p. 116).

Os dados desse estudo mostram contradições entre o dito pelos sujeitos e o que o pesquisador observou durante o processo de investigação, sobretudo no 
que tange à constatação acerca da influência que os resultados do Enade exercem na gestão dos currículos dos cursos das IES analisadas.

Na mesma linha de investigação, o estudo WORDELL, 2012de Oliveira (2011) teve como objetivo observar como os processos avaliativos são percebidos pelos gestores, discentes e docentes do curso de Pedagogia de duas instituições privadas. O estudo mostrou que os sujeitos envolvidos no processo avaliativo se sentem responsáveis pela melhoria das instituições e que a avaliação pode contribuir para melhorar a qualidade do ensino por ela oferecido.

É interessante observar que os aspectos positivos da avaliação institucional no trabalho dos professores estão relacionados ao "currículo em ação", sobretudo no que se refere aos aspectos didático-pedagógicos que incidem sobre a sala de aula, relacionamento com os estudantes e melhoria dos resultados das avaliações de desempenho dos estudantes. Essa constatação reforça os aspectos acadêmicos dessa avaliação, sobretudo daqueles voltados à melhoria dos processos ensinoaprendizagem e consequentemente, à melhoria da qualidade dos cursos e da IES, considerados os mais "legítimos" no campo da avaliação educacional (DIAS SOBRINHO, 2002).

O estudo de Fonseca (2006) teve como objetivo identificar os sentidos que a autoavaliação tem para os professores de um Centro Universitário e mostrou que eles não estabelecem relações diretas e imediatas entre seu trabalho cotidiano e os processos de avaliação institucional, nem as relações desta com a autoavaliação da qual participam, pois "o nível de participação dos professores nestes processos é muito mais na sua execução do que na sua concepção" (p. 32), numa demonstração clara de que a avaliação não é acompanhada da abertura de canais participativos para a vida acadêmica. Ainda de acordo com o autor "a avaliação passa ao largo da vida dos professores e que por isto não ganham o sentido formativo esperado na sua ação" (p. 33).

Nessa direção e com resultados semelhantes, o trabalho de Conceição (2011), realizado na Universidade Federal do Tocantins, objetivou reconstruir a trajetória avaliativa do primeiro ciclo do Sinaes naquela universidade, ocorrido nos anos 2006/2007, e avaliar o segundo processo, ocorrido nos anos 2009/2010, por meio de uma análise que possibilitou identificar as concepções de avaliação que subsidiaram a construção dos dois processos e que nortearam as ações da Comissão Própria de Avaliação (CPA), na tentativa de perceber essas avaliações como contraponto ao que preconiza o Sinaes. Os resultados mostraram "grande fragilidade na avaliação institucional da UFT, sobretudo na categoria participação" (p. 112). Esse fato foi bastante pontuado por todos os segmentos da universidade, tanto avaliados quanto avaliadores. A autora observou que a pouca participação 
dos envolvidos na avaliação pode sinalizar fragilidades no processo no qual a avaliação assume mais as funções regulatórias do que emancipatórias.

As conclusões dos estudos de Fonseca (2006) e Conceição (2011) revelam significativa fragilidade nos processos de avaliação institucional analisados, sobretudo no que diz respeito à participação dos envolvidos.

Por fim, o estudo realizado por Sousa (2012) abordou as repercussões do Sinaes nas práticas avaliativas dos professores de um curso de Pedagogia, partindo das seguintes questões: (a) a relação existente entre as práticas avaliativas dos professores do ensino superior e a avaliação externa promovida pelo Enade; b) como os professores desenvolvem suas práticas avaliativas, especialmente a elaboração de questões dissertativas presentes em testes. A investigação revelou

\footnotetext{
Uma relação de exclusão entre as práticas avaliativas dos partícipes desta pesquisa e os sentidos por eles atribuídos ao Enade, uma vez que em seus discursos os professores denotam as funções de controle, de seleção e de classificação presentes no exame externo promovido pelo Enade e o distanciamento deste da realidade dos sujeitos do processo: alunos e professores (p. 75).
}

As conclusões desse estudo revelam que os professores participantes da pesquisa conhecem alguns princípios fundamentais dos processos de avaliação, pois conseguem discernir que os objetivos e a metodologia utilizados para a realização dos exames em larga escala são bem distintos dos propósitos que a avaliação da aprendizagem sugere.

Enquanto o primeiro visa à seleção e à classificação ao final de uma etapa, a segunda visa ao diagnóstico dos problemas ocorridos na aprendizagem dos alunos para que sejam corrigidos ao longo do processo ensino-aprendizagem. Portanto, não é conveniente nem desejável que sejam reproduzidas práticas e modelos de exames em larga escala no âmbito da sala de aula. Quando se faz isso, faz-se com o intuito de treinar os estudantes para que façam exames e neles obtenham boas notas, ficando em plano secundário o currículo escolar e o conhecimento, o que pode provocar distorções na formação dos educandos, sobretudo deixando lacunas quanto aos saberes do currículo, que não são objeto de avaliação nos exames nacionais padronizados.

\section{OUTRAS CONSIDERAÇÕES}

A análise dos resultados desses estudos precisa levar em conta o contexto político de vigência dos dois modelos de avaliação das instituições bem como suas características essenciais, manifestas na exposição dos resultados dos estudos apresentados. 
As consequências dos resultados dessa avaliação na vigência do ENC não foram isoladas das consequências de outras políticas vigentes naquele período, sobretudo nos anos 1990, dentre as quais se destacam a forte expansão da rede privada, a ausência de investimentos públicos na rede federal e, consequentemente, forte pressão sobre os professores das duas redes de ensino superior, sendo que em cada uma delas essas consequências viriam de maneiras distintas, mas quase sempre perversas.

Conforme se pode ver em um dos estudos apresentados, na vigência do ENC houve grande desvalorização dos docentes na rede federal, causada principalmente pela estagnação dos investimentos nas IFES e congelamento de salários dos professores, o que induziu a uma fuga massiva de professores qualificados, por meio de aposentadorias precoces, sobrecarregando aqueles que permaneceram e, de outro lado, na rede privada, em grande expansão estimulada pelo modelo privatista adotado pelo então presidente Fernando Henrique Cardoso, os docentes foram contratados de forma precária, na maior parte como aulistas e sem perspectivas de carreira.

O mesmo não ocorre no contexto de vigência do Sinaes, em que houve um esgotamento da expansão privada, quando as IES passaram a registrar grande número de vagas ociosas, uma vez que as famílias já não poderiam mais arcar com os custos das mensalidades (AMARAL, 2003). Nesse contexto, no segundo mandado do Presidente Lula houve significativa expansão da rede federal de educação superior, tanto das universidades como dos institutos federais. A mudança de rumos das políticas educacionais sinalizou para uma maior valorização da educação superior pública, mas que pouco alterou as condições impostas aos professores da rede privada, que passou a viver novo ciclo de crescimento, por meio de fusões e aquisições das instituições por grandes corporações do mercado educacional (SGUISSARDI, 2014).

Em geral, constatou-se que nas IES privadas o trabalho dos professores foi mais intensificado, por meio de contratos de trabalho precários, sem carga horária para atividades extraclasse, além de serem elas pressionadas a promover a melhoria da performance dos alunos nas provas do Enade. Além disso, houve trabalhos em que foi relatada a adoção de políticas institucionais voltadas a adequar o quadro docente às exigências do MEC no caso de cursos cujas notas ficaram abaixo da média por duas avaliações consecutivas, o que levou à demissão de professores antigos sem a titulação adequada e a contratação de novos professores, em contratos temporários ou como aulistas. $\mathrm{O}$ que deveria redundar em melhores condições de trabalho dentro das instituições acabou transformando-se em mais um problema para os professores. 
Outros aspectos que se destacam nos resultados éque algumas repercussões da avaliação ocorreram no âmbito pedagógico-didático, especificamente no modo como os professores avaliam os alunos, que passaram a elaborar instrumentos avaliativos com características semelhantes às questões das provas aplicadas no Enade. Constatou-se ainda que os gestores das IES passaram a organizar mais encontros formativos com os professores para discutir o currículo dos cursos visando a sua adequação aos conteúdos que compõem a matriz de referência do exame, bem como à realização de projetos institucionais voltados à orientação dos estudantes quanto à realização da prova. É relevante destacar, também, os perigos que essa adaptação curricular representa para a formação dos futuros profissionais, sobretudo por implicar um explícito reducionismo curricular, conforme estudos de Freitas (2012) e Sousa (2012).

Observou-se grande destaque à avaliação de desempenho dos alunos, o Enade, pelos participantes dos estudos analisados, sobretudo por ter este assimilado as características do antigo Provão e se tornado indutor de mudanças curriculares nas IES privadas. Seus resultados também têm definido a situação dos professores nos cursos, responsabilizados pela produção de bons resultados no ranking, tendo em vista que uma boa nota no Enade pode significar maior demanda por seus cursos, além de assegurar a manutenção das bolsas de estudos do Prouni, o que, atualmente, consiste em importante fonte de recursos para o setor privado de ensino superior.

Finalmente, a análise dessas pesquisas explicitou um potencial para induzir mudanças positivas no âmbito da autoavaliação institucional, que, no contexto do Sinaes, é conduzida pela Comissão Própria de Avaliação, a CPA, e pelos Núcleos Docentes Estruturantes, os NDEs de cada curso. Os estudos revelam que a avaliação das instituições e de seus respectivos cursos deveria ser mais bem coordenada e divulgada pelas IES, visando a corrigir as fragilidades e lacunas existentes no processo de comunicação e de participação dos professores. Observou-se, aindam que, em geral, as avaliações institucionais têm sido conduzidas, sobretudo, para atender às exigências do MEC, nem sempre cumprindo seu papel de indutor de reflexões e mudanças no interior dos cursos e das IES. Dessa forma, empreendem-se grandes esforços na sua condução e não se colhem os bons frutos que ela, potencialmente, poderia oferecer às comunidades acadêmicas. 


\section{REFERÊNCIAS}

AFONSO, A. J. Para uma concetualização alternativa de accountability em educação. Revista Educação e Sociedade.Vol. 33, número 119, abr.- jun 2012, p. 471-484. São Paulo: Cortez; Campinas, Cedes, 2012.

AMARAL, Nelson Cardoso. Financiamento da educação Superior. Estado X Mercado. São Paulo: Cortez, 2003.

ANDRIOLA, Cristiany Gomes. Avaliação da atuação dos docentes de instituições de ensino superior (IES): o caso da Faculdade Cearense (FAC). 2011. 81 f. Dissertação (Mestrado Profissional em Políticas Públicas e Gestão da Educação Superior) - Universidade Federal do Ceará, Fortaleza, 2011.

ASSIS, Lúcia Maria de. Avaliação institucional e prática docente na educação superior: tensões, mediações e impactos. 2008. 249 f. Tese (Doutorado em Educação) - Universidade Federal de Goiás, Goiânia, 2008.

; AMARAL, Nelson Cardoso. Avaliação da Educação: por um sistema nacional. In: Retratos da Escola/ CNTE. Editora Esforce, v. 7, no 12, jan-jun 2013. Brasilia: CNTE, 2013.

AVILA, Sueli de Fátima Ourique de. As Transformações do Trabalho Docente através da Produção Escrita da Anped (1996-2009). 34ª Anped, GT 09, Anais..., Rio de Janeiro: UERJ, 2011.

BERTELLI, Eliseu Miguel. Avaliação Institucional: trajetória da Faculdade de Pato Branco (FADEP). 2004. 148f. Dissertação (Mestrado em Educação) Pontifícia Universidade Católica do Paraná, Curitiba, 2004.

CONCEICAO, Maria de Fatima da. Política de Avaliação da Educação Superior da Universidade Federal Do Tocantins-UFT no Contexto do Sinaes: entre Avaliadores e Avaliados. 2011. 154 f. Dissertação (Mestrado Profissional em Avaliação de Políticas Públicas) - Universidade Federal do Ceará, Fortaleza, 2011. 
CORREIA, Anna Elizabeth Galvão Coutinho. A Influência Exercida pelo Sistema de Avaliação da Capes na Produção Científica dos Programas de Pós-Graduação em Física. 2012, 214 f. Tese (Doutorado em Ciências da Informação - Universidade Federal de Minas Gerais. Belo Horizonte, 2012.

COSTA, Janine de Lucena. E agora? Quem me avalia é o aluno: um estudo sobre a avaliação do desempenho docente. 2007. 119 f. Dissertação (Mestrado em Educação) - Universidade de Brasília, Brasília, 2007.

DIAS SOBRINHO, José. Universidade e Avaliação: entre a ética e o mercado. Florianópolis: Insular, 2002.

Avaliação, políticas Educacionais e Reformas da educação Superior. São Paulo: Cortez, 2003.

. Avaliação da educação Superior. Petrópolis: Ed. Vozes, 2000.

FONSECA, Andréa Augusta. A avaliação institucional e os sentidos da autoavaliação para os professores do Centro Universitário SENAC. 2006, 136 p. Dissertação (Mestrado em Educação) - Universidade Metodista de São Paulo, São Bernardo do Campo, 2006.

FREITAS, Luiz Carlos de. Os reformadores empresariais da educação: da desmoralização do magistério à destruição do sistema público de educação. In: Revista Educação e Sociedade. Vol. 33, número 119, abr.- jun 2012. São Paulo: Cortez; Campinas, Cedes, 2012.

MARINS, Isabela Cristina. A Política de Avaliação da Pós Graduação. 2012. 200 f. Dissertação (Mestrado em Educação) - Universidade Católica de Brasília, Brasília, 2012

MARTINS, Maria Inês. Impactos do exame nacional de cursos e da qualificação do corpo docente sobre o curso de odontologia da PUC Minas. 23 a Anped GT 11, Anais. Caxambu, 2000.

MAUÉS, Olgaíses. A política de educação superior para a formação e o trabalho docente: a nova regulação educacional.. 31ª Anped, GT-11, UFPA: Anais...2008. 
MOTA JUNIOR, William Pessoa da. Os Impactos do Sistema Capes de Avaliação sobre o Trabalho Docente na Pós-Graduação: o Caso da UFPA, 2011. 208 f. . Dissertação (Mestrado em Educação) - Universidade Federal do Pará, Belém, 2011.

NICHES, Cláudia Cardoso. O Mal-Estar Docente na Perspectiva de Professores de História. 34 anped, GT 08, UNISINOS: Anais... 2011.

OLIVEIRA, Ana Paula Vasconcelos de. Avaliação Institucional: Desempenho Docente na Educação Superior. 2011. 101 f. Dissertação (Mestrado em Educação) - Universidade Federal do Ceará, Fortaleza, 2011.

RIBEIRO, Elisa Antonia. As atuais políticas públicas de avaliação para a educação superior e os impactos na configuração do trabalho docente. Revista Avaliação (Campinas) [online]. vol.17, n.2, p. 299-317, 2012. Disponível em: http://www. scielo.br/scielo.php?script=sci_arttext\&pid=S1414-40772012000200002.

SANCHES, Maria Geli. Avaliação institucional no ensino superior: um estudo de caso. 2010. 159f. Dissertação (Mestrado Interinstitucional em Educação) Pontifícia Universidade Católica de Goiás/Centro Universitário de Anápolis (UniEvangélica), Goiânia, 2010.

SGUISSARDI, Valdemar. Estudo diagnóstico da política de expansão da (e acesso à) educação superior no Brasil 2002-2012. Projeto de Organismo Internacional OIE/BRA/10/002, Edital n. 051/2014 SESU. Piracicaba/SP; Brasília/DF 2014.

;SILVA Jr. João dos Reis. Trabalho Intensificado nas federais, pósgraduação e produtivismo acadêmico. São Paulo: Xamã, 2009.

SILVA, Assis Leão. Impasses e perspectivas das CPAs após a introdução dos índices gerais. 34 anped, Anais... GT 11. Recife: UFPE, 2011.

SILVA, Maria das Graças Martins. Trabalho docente na pós-graduação: a lógica da produtividade em questão. 2008. (Doutorado em Educação) - Universidade Federal do Rio Grande do Sul - _Porto Alegre, 2008

SINAES - Sistema Nacional de avaliação da educação Superior: da concepção à regulamentação / Instituto Nacional de estudos e Pesquisas educacionais Anísio Teixeira, $4^{a}$ ed. Brasília : Inep, 2007. 
SOUSA, Jose Ribamar de Brito. Práticas avaliativas de elaboração de testes, especialmente de questões dissertativas, utilizadas pelos professores do curso de Pedagogia da Fap/Teresina e os sentidos de Enade. 2012. $136 \mathrm{f}$. (Mestrado em Educação) - Universidade Federal do Piauí, Terezina, 2012.

SOUSA, José Vieira. Racionalidades e práticas no uso dos resultados do Enade 2008: o caso dos cursos de licenciatura da Universidade de Brasília. 34 anped, Anais Natal/RN. GT 11, 2011.

SOUSA, José Vieira de. Qualidade na Educação Superior: Lugar e Sentido na Relação Público-Privado. Cad. Cedes, Campinas, vol. 29, n. 78, p. 242-256, maio/ago. 2009. Disponível em: http://www.scielo.br/pdf/ccedes/v29n78/ v29n78a07.pdf.

SOUZA, Sandra Zákia Lian de e REAL, Giselle Martins. Resultados e vicissitudes da avaliação da educação superior: mecanismos implementados em Mato Grosso do Sul (1995 a 2002). Educação e Sociedade [online]. vol. 30, n.107, p. 469-488, 2009. Disponível em: http://dx.doi.org/10.1590/S0101-73302009000200009.

TIRADENTES, Aparecida de. “Tem que fazer! Se não fizer, não trabalha mais aquil": trabalho docente e formação humana no quadro de internacionalização, fusões, Laquisições e reestruturação do "mercado" da educação superior. 33 Anped GT 09, Caxambu: Anped, 2010.

WORDELL, Eleni Hosokawa. Conceito Cinco no Enade em Cursos de Pedagogia: que Referenciais estão em Jogo? 2012. 255 f. Dissertação (Mestrado em Educação) - Universidade de Brasília, Brasília, 2012.

LÚCIA MARIA DE ASSIS é pedagoga pela Pontifícia Universidade Católica de Minas Gerais, PUC/MG (1984), mestre em Educação pela Universidade Metodista de Piracicaba, Unimep (2001), doutora em Educação pela Universidade Federal de Goiás, UFG (2008) e pós-doutora pela Universidade de São Paulo, USP (2014). Professora na graduação e pós-graduação (PPGE) da Faculdade de Educação da Universidade Federal de Goiás, na linha de pesquisa Estado, Políticas e História da Educação. Editora da Revista Brasileira de Política e Administração da Educação (RBPAE). Atua na área de Políticas de avaliação, gestão e formação de professores na educação superior. 